\title{
Effect of the First World War on suicide rates in Ireland: an investigation of the 1864-1921 suicide trends
}

\author{
Mugtaba Osman and Andrew C. Parnell
}

\section{Summary}

Since the proposition of the social integration theory by Émile Durkheim, macro-sociological changes have been speculated to affect suicide rates. This study investigates the effect of the First World War on Irish suicide rates. We applied an interrupted time series design of 1864-1921 annual Irish suicide rates. The 1864-1913 suicide rates exhibited a slowrising trend with a sharp decline from the year 1914 onwards. The odds for death by suicide for males during the 1914-1918 period was 0.811 (95\% Cl 0.768-0.963). Irish rates of suicide were significantly reduced during the First World War, most notably for males.

\section{Declaration of interest}

None.

\section{Copyright and usage}

(c) 2015 The Royal College of Psychiatrists. This is an open access article distributed under the terms of the Creative Commons Non-Commercial, No Derivatives (CC BY-NC-ND) licence.
Macro-sociological changes have long been speculated to affect suicide rates across age groups. ${ }^{1,2}$ In the late 1870s, Enrico Morselli suggested that the suicide rate decreases at times of war when compared with times of peace. ${ }^{3,4}$ Later, in the late 1890 s, Émile Durkheim went on to further confirm this counterintuitive inverse relationship between war and suicide rates. He attempted to explain this phenomenon via what he called 'the social integration model'. This postulated that the drop in suicide rates results from a shift in the focus of individuals from their own suicidal wishes to a more collective goal of tackling the external threat. ${ }^{5}$ Several European studies that investigated how the first and second world wars affected suicide rates across France, Great Britain, and Scotland were in support of Durkheim's assertion. ${ }^{6-8}$ Over 200000 Irish men fought in the First World War, of whom 50000 are believed to have died; this is equivalent to an annual death rate of 225 per 100000 of the population. ${ }^{9,10}$ The effect of the First World War on the Irish suicide rate has received limited attention from sociological and psychological researchers. This study sets out to investigate such an effect, if any.

\section{Method}

Suicide data in Ireland between 1864 and 1921 were gathered from the archive section of the Central Statistics Office's website. ${ }^{11}$ We chose this range to focus the attention analysis on the effect of the First World War. We adopted an interrupted time series design. We model the natural logarithm of suicide rates per 100000 for the years 1864-1921 using autoregressive integrated moving average with explanatory variable (ARIMAX) approach, that was successfully used before in a number of medical and non-medical studies. ${ }^{12-14}$ We then calculated the coefficient for an indicator variable for the effect of First World War non-zero only for the years 1914-1918 and zero otherwise. Statistical analysis was performed using the $\mathrm{R}$ statistical package version 3.1.2. (http://beta.r-project.org).

\section{Results}

A noticeable slow-rising trend was present in terms of the suicide rates in Ireland from 1864 up to the year 1913. The average suicide rate for this period was 2.49 per 100000 . However, a sharp decline was noted from the year 1914 onwards, with an average of 2.64 suicides per 100000 (Fig. 1). This trend was clear even when the suicide rates were calculated for men and women separately.

The year 1912 witnessed the highest overall suicide rate of 3.763 suicides per 100000 of the population and the highest suicide rate for men at 5.938 per 100000 , whereas the year 1910 witnessed the highest female suicide rate of 1.957 suicides per 100000 of the population.

The highest male-to-female ratio in terms of suicide rates was 6.17 and was observed in the year 1920 .

The year 1866 witnessed the lowest overall suicide rate of 1.213 suicides per 100000 of the population and the lowest suicide rate for men at 1.666 per 100000 , whereas the year 1920 witnessed the lowest female suicide rate of 0.586 suicides per 100000 of the population.

On investigating the effect of First World War on the overall suicide rate, the coefficient in the interrupted ARIMA model was $-0.172(95 \%$ CI -0.305 to -0.040$)$ which was statistically significant $(P=0.011)$. The odds for death by suicide for the total Irish population during the 1914-1918 period were calculated as 0.842 (95\% CI 0.787 to 0.901 ). This translates to a reduction in the suicide rates for men by $13.6 \%$ (95\% CI 9.9 to 21.1). However, the coefficient for the effect of First World War on female suicide rate was -0.103 (95\% CI -0.340 to 0.134$)$ which was not statistically significant $(P=0.394)$, although the confidence interval contains

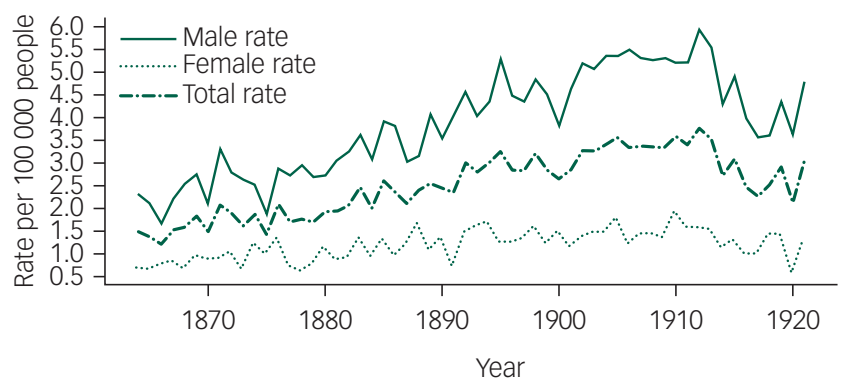

Fig. 1 The 1864-1921 annual suicide rates per 100000 of the population in Ireland 
effect sizes comparable to that of the other groups. On the other hand, the coefficient for the effect of First World War on male suicide rate was -0.210 (95\% CI -0.374 to -0.045$)$ which was statistically significant $(P=0.013)$. The odds for death by suicide for males during the 1914-1918 period was found to be 0.811 (95\% CI 0.768 to 0.963 ). In other words, during the 5 years of the First World War there was a significant reduction in suicide rates for men by $18.9 \%$ (95\% CI 3.7 to 24.2 ).

\section{Discussion}

At the time of the First World War, Ireland was part of the British Empire, and Irish soldiers served in the British Army. Although the psychological consequences of this war on Irish soldiers and the Irish public were studied sparsely, these may be reasonably believed not to differ profoundly from their British and European counterparts. In his investigation of suicide rates between 1901 and 1965, Lester found that suicide rates were lower during wartime in Great Britain. ${ }^{5}$ However, this was not a large effect. In a study performed in the late 1940s, a sharp decrease in suicide rates in France, specifically in Paris, was noted during the First World War by Lunden. ${ }^{4}$ The rates of French suicides, as Lunden established, continued to decrease even in the decade following the First World War. According to our findings, the Irish case has a number of similarities to findings by these researchers. The overall trend has taken a downward direction after the year 1914 as can be seen clearly in Fig. 1. However, applying more advanced statistical procedures, only the decrease in total suicide rate and male suicide rates can be supported by statistical evidence. Females' suicide rate reduction during wartime was not different from peacetime. Divergence of male and female suicide rates was thought to be a more recent phenomenon. ${ }^{15}$ Indeed, our paper shows support for this as the trends were roughly similar between the two genders.

An important limitation to this investigation is the potential under-reporting of suicide deaths that may have been worsened by the difficulties faced by local registrars, whose knowledge, training and experience may vary considerably, during wartime. However, to our knowledge, this is the first study to specifically evaluate the effect of the First World War on Irish rates of suicide. Data were only available for the whole Irish population, i.e. the 32 counties, and it could have been more interesting to investigate the effect of the First World War on people living south and north of the borders separately.

Irish rates of suicide were reduced during the First World War most notably for males. This provides some further support to
Durkheim's social theory of suicide indicating that Irish men may have focused on the collective goal of defending their island rather than their suicidal wishes during the 1914-1918 war.

Mugtaba Osman, MBBS, MRCPsych, St Brigid's Hospital, Ardee, Co. Louth, Ireland; Andrew C. Parnell, CStat, School of Mathematical Sciences, Insight: the National Centre for Data Analytics, University College Dublin, Belfield, Dublin, Ireland

Correspondence: Mugtaba Osman, St Brigid's Hospital, Ardee, Co. Louth, Ireland. Email: mugtaba.osman@ucdconnect.ie

First received 19 Mar 2015, final revision 16 Oct 2015, accepted 22 Oct 2015

\section{References}

1 Miley JD, Micklin M. Structural change and the Durkheimian legacy: a macrosocial analysis of suicide rates. Am J Sociol 1972; 78: 657-73.

2 Giles-Sims J, Lockhart C. Explaining cross-state differences in elderly suicide rates and identifying state-level public policy responses that reduce rates. Suicide Life Threat Behav 2006; 36: 694-708.

3 Goldney RD, Schioldann JA. Pre-Durkheim suicidology. Crisis 2000; 21: 181-6.

4 Morselli H. Suicide. Kegan Paul \& Co., 1881.

5 Durkheim E. Le suicide. Alcan, 1897

6 Lunden WA. Suicides in France, 1910-1943. Am J Sociol 1947; 52: 321-34.

7 Lester D. Involvement in war and suicide rates in Great Britain, 1901-1965. Psychol Rep 1994; 75: 1154

8 Henderson R, Stark C, Humphry RW, Selvaraj S. Changes in Scottish suicide rates during the Second World War. BMC Public Health 2006; 6: 167.

9 Ireland's Memorial Records. Department of Foreign Affairs, 14 August 2014. Available at: http://imr.inflandersfields.be

10 Bartlett T, Jeffery K. A military history of Ireland. In Militarism in Ireland (ed. D Fitzpatrick): 383-9. Cambridge University Press, 1996.

11 Central Statistics Office. Annual reports on marriages, births and deaths in Ireland from 1864 to 2000. CSO, 2014. Available at:http://www.cso.ie/en/statistics/births deathsandmarriages/archive/annualreportsonmarriagesbirthsanddeathsinirelandfrom1864to2000/

12 Low RB, Bielory L, Qureshi Al, Dunn V, Stuhlmiller DF, Dickey DA. The relation of stroke admissions to recent weather, airborne allergens, air pollution, seasons, upper respiratory infections, and asthma incidence, September 11, 2001, and day of the week. Stroke 2006; 37: 951-7.

13 Williams BM. Multivariate vehicular traffic flow prediction: evaluation of ARIMAX modeling. Transp Res Rec 2001; 1776: 194-200.

14 Fan J, Shan R, Cao X, Li P. The analysis to tertiary-industry with ARIMAX model. J Math Res 2009; 1: 156-163.

15 Stack S. Suicide: a 15-year review of the sociological literature. Part I: cultural and economic factors. Suicide Life Threat Behav 2000; 30: 145-62. 